Heins, M.J., Lorenzi, M.F., Korevaar, J.C., McBride, M.L. Non-oncology physician visits after diagnosis of cancer in adolescents and young adults. Journal of Cancer Survivorship: 2016, 10(4), 783-788

\begin{tabular}{|l|l|}
\hline $\begin{array}{l}\text { Postprint } \\
\text { Version }\end{array}$ & 1.0 \\
\hline Journal website & http://link.springer.com/article/10.1007\%2Fs11764-016-0523-x \\
\hline Pubmed link & $\underline{\text { http://www.ncbi.nlm.nih.gov/pubmed/26874737 }}$ \\
\hline DOI & $10.1007 / \mathrm{s} 11764-016-0523-\mathrm{x}$ \\
\hline
\end{tabular}

This is a NIVEL certified Post Print, more info at http://www.nivel.eu

\title{
Non-oncology physician visits after diagnosis of cancer in adolescents and young adults
}

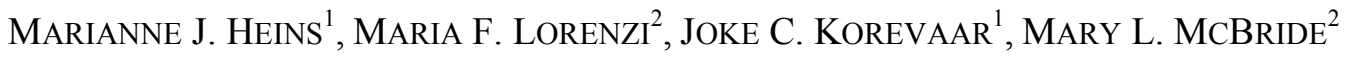 \\ ${ }^{1}$ Netherlands Institute for Health Services Research (NIVEL) \\ ${ }^{2}$ BC Cancer Research Centre, BC Cancer Agency
}

\begin{abstract}
Purpose: Health care needs of adolescents and young adults (AYAs) with cancer are probably different from other age groups. Studying their non-oncology physician visits in the first years after diagnosis may provide insight into the specific health problems AYA patients experience and thereby help to improve care for these patients.

Methods: Seven hundred seventy-four AYAs identified from a Canadian provincial registry diagnosed with cancer between ages 15 and 24 years in 1991/2001 were included, matched by birth year and sex to ten controls. Based on provincial health insurance plan records, we determined the number of family physician and non-cancer specialist visits in the 5 years after diagnosis (for patients) or inclusion (for controls).

Results: The percentage of patients visiting a non-cancer specialist decreased from 96 to $49 \%$ over the 5-year period. The percentage visiting a family physician decreased from 96 to $84 \%$. Visits in all years were significantly higher than among controls. In the first year after diagnosis, many patients visited a non-cancer specialist or a family physician for neoplasm-related health problems (77 and $55 \%$, respectively). In addition, family physicians were also consulted for general age-specific problems, such as genitourinary symptoms Conclusions: In the first years after diagnosis of cancer in AYAs, both noncancer specialist and family physician visits are common, although non-cancer specialist visits are less common and decline considerably faster than in younger children.

Implications for Cancer Survivors: The specific pattern of physician visits of this age group calls for care that is tailored to their specific needs.
\end{abstract}


Heins, M.J., Lorenzi, M.F., Korevaar, J.C., McBride, M.L. Non-oncology physician visits after diagnosis of cancer in adolescents and young adults. Journal of Cancer Survivorship: 2016, 10(4), 783-788

\section{Electronic supplementary material}

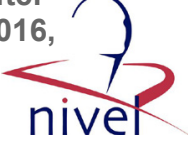

The online version of this article (doi:10.1007/s11764-016-0523-x) contains supplementary material, which is available to authorized users.

\section{INTRODUCTION}

During recent decades, large steps have been made in the detection and treatment of cancer, but the progress in adolescents and young adults (AYAs) has been only modest. The number of new patients in this age group has risen faster than in younger or older age groups, while improvement in survival has not been as rapid [1-3]. This is probably due to a combination of several factors: the unique distribution of cancer types seen in AYAs and age-specific biologic variation in those cancers, limited availability of care specialized for AYAs because of the dichotomy between pediatric and adult care, and lack of (participation in) research [4-6]. Patients and physicians both acknowledge that there is a need for health care that addresses the unique needs of this age group [7].

The effect of cancer in AYAs may be different from that in children or adults. A diagnosis of cancer and its treatment may impact the usual developmental changes that take place during adolescence or young adulthood $[8,9]$ and can therefore have profound impact on physical, mental, and social functioning [10]. Indeed, AYAs with cancer have poorer physical and mental health than their peers without cancer, during the active treatment period [11] as well as years after diagnosis [12, 13]. To improve care for AYAs, more knowledge about the specific care needs of AYAs with cancer is needed $[14,15]$.

Primary and non-cancer specialist visits by AYAs in the first years after diagnosis of cancer have not previously been studied. We therefore do not know how much care AYAs with cancer receive, who provides this care, and for which health problems they receive health care. Studies on children who were diagnosed with cancer before the age of 15 show that they have increased physician visits, both in primary and secondary care, more than 5 years after diagnosis [16-19].

However, monitoring of AYAs with cancer in the cancer setting is variable.

Adolescents treated in pediatric facilities are required to leave care at 18 years of age, as the mandate of these facilities ends at that age. Those treated in adult facilities generally have less follow-up than in the pediatric setting. Many AYAs perceive barriers to continuing follow-up care, particularly within the cancer care setting [20]. In younger patients, follow-up visits are largely determined by their parents, but this shifts as patients grow toward adulthood. AYAs often see themselves as healthy again and do not want to remain in a place that reminds them of their prior cancer and future risks or treats them as chronically ill [20]. They may therefore also visit a non-cancer specialist or family physician for health problems related to cancer or its treatment.

Using the linked provincial registry, clinical, and administrative datasets of the Childhood, Adolescent, and Young Adult Cancer Survivor (CAYACS) Research Program of British Columbia, Canada [21], we examined both primary and noncancer specialist physician visits in the first years after diagnosis of cancer in AYAs and compared it to that of non-cancer controls of the same age and sex. We looked at both the number of visits and the reasons for these visits. 
Heins, M.J., Lorenzi, M.F., Korevaar, J.C., McBride, M.L. Non-oncology physician visits after diagnosis of cancer in adolescents and young adults. Journal of Cancer Survivorship: 2016, 10(4), 783-788

\section{METHODS}

\section{Study population}

For this study, we identified patients from the British Columbia (BC) cancer registry. Eligible patients were those with a diagnosis of a primary cancer between 1991 and 2001, aged between 15 and 24 years at diagnosis [22], residence in the province of $\mathrm{BC}$ at time of diagnosis, and successful linkage to registration files from the provincial health insurance plan using a unique personal health number (PHN) (BC Vital Statistics Agency [McBride] (2012): Vital Statistics Deaths. Population Data BC BC Cancer Agency. Data Extract BC Vital Statistics Agency (2012). http://www.popdata.bc.ca/data; British Columbia Ministry of Health [Mc Bride] (2013): Medical Services Plan (MSP) Payment Information File. Population Data BC BC Cancer Agency. Data Extract. MOH (2012). http://www.popdata.bc.ca/data). For each patient, ten controls of the same birth year and sex were selected from the provincial health insurance plan registry.

\section{Data collection}

Data on health care use of both patients and controls were retrieved from the provincial health insurance plan, containing records of all medically necessary physician-ordered outpatient services of residents of BC since 1986. Diagnoses were coded using the International Classification of Diseases (ICD) [23]. Available data on family physician and non-cancer specialist visits and diagnoses made during these visits were extracted from time of diagnosis (for patients) or inclusion (for controls) to 5 years after this date. Data were right-censored if AYAs died or they moved out of BC. Clinical data of patients (i.e., diagnosis, treatment, relapse status) was available as part of the CAYACS Program [21]. Residence of both patients and controls, recorded as annual postal code, was retrieved from the provincial health insurance plan and used to link to census data to generate area-specific socioeconomic status, region (i.e., regional health administration area), and urban or rural.

\section{Analysis}

The percentage of family physician and non-cancer specialist visits was first compared between cancer patients and controls in each year using a X 2 test. We then calculated the mean number of family physician and non-cancer specialist visits in those cancer patients and controls who had a visit and compared them using multiple negative binomial regression analyses [24]. We chose this type of regression analysis since our outcome variable, the number of visits, is a rate and this type of regression predicts the rate of an event. For each year after the diagnosis or inclusion, we built a model with the number of visits as dependent and patient/control status as independent variable.

We then examined the reasons that were recorded for each visit, by calculating the percentage of patients and controls with a visit for each ICD chapter. Finally, we calculated the percentage of patients and controls with a visit for each specialty. Analyses were performed using IBM ${ }^{\circledR}$ SPSS ${ }^{\circledR}$ version 21 . A p value below 0.05 was considered statistically significant. 
Heins, M.J., Lorenzi, M.F., Korevaar, J.C., McBride, M.L. Non-oncology physician visits after diagnosis of cancer in adolescents and young adults. Journal of Cancer Survivorship: 2016, 10(4), 783-788

\section{RESULTS}

In the BC cancer registry, 774 AYAs between the age of 15 and 24 years were identified who received a diagnosis of cancer between January 1991 and December 2001. These patients were matched on birth year and sex to 7753 controls. Cancer patients and controls did not differ significantly on any baseline characteristics (Table 1). Clinical characteristics of the patients are provided in Table 2. Most frequent cancer types were lymphoma, carcinoma, and germ cell tumors, and $45 \%$ of the patients had been treated with chemotherapy.

\section{[TABLE 1] [TABLE 2]}

In the first year after diagnosis, almost all cancer patients visited a family physician and a non-cancer specialist (both $96 \%$, Table 3). This was significantly more than the controls, of whom $79 \%$ visited a family physician and only $29 \%$ a non-cancer specialist. The percentage of patients with a non-cancer specialist or family physician visit declined during the first 5 years after diagnosis to $84 \%$ for family physician and $49 \%$ for non-cancer specialist visits, but the visit rate was still significantly higher than for the controls. The patients with a visit had a mean of ten family physician and nine non-cancer specialist visits in the first year, compared to six and three in controls, respectively. The number of visits in patients dropped to about seven family physician and four non-cancer specialist visits in the fifth year after diagnosis, which was still significantly higher than in the controls.

\section{[TABLE 3]}

In the first year after diagnosis, the most frequent reasons for patients to visit a family physician were "neoplasms" and "signs and symptoms" (Fig. 1). Signs and symptoms comprised a wide variety of health problems, mostly "general symptoms" ( $24 \%$ ), or problems related to the nervous system (15\%) or skin (13\%) (see appendix 1). In the fifth year after diagnosis, the percentage of patients who visited the family physician for neoplasms had decreased considerably, but the percentages of patients with a family physician visit related to signs and symptoms remained elevated (54 vs. $44 \%$ in controls, $p<0.001$ ). Other common reasons for family physician visits were "additional codes," which were most commonly related to discussing results of laboratory tests $(33 \%)$ and prenatal care $(22 \%)$ and respiratory problems, mainly acute respiratory infections. Finally, genitourinary problems, mostly disorders of menstruation $(30 \%)$, were quite common, but these were equally common in controls ( 23 vs. $21 \%, p=0.26)$ ).

\section{[FIGURE 1]}

For non-cancer specialist visits, neoplasms were by far the most frequent reason for visit throughout the first 5 years after diagnosis, although the percentage of patients with such a visit decreased significantly over time (Fig. 2). Other common reasons for visit in the first year after diagnosis were additional codes, mainly to discuss results of laboratory tests ( $78 \%$ ), and signs and symptoms, comprising a variety of general symptoms (12\%) and symptoms related to the respiratory system $(15 \%)$, 
Heins, M.J., Lorenzi, M.F., Korevaar, J.C., McBride, M.L. Non-oncology physician visits after diagnosis of cancer in adolescents and young adults. Journal of Cancer Survivorship: 2016, 10(4), 783-788

nervous system (12\%), or head and neck (11\%). Many patients also visited a noncancer specialist for neurological problems, mainly epilepsy $(11 \%)$ and various eye problems. Visits related to "injury and poisoning" were also quite common and were mostly related to complications of medical care $(61 \%)$. All reasons for visit were significantly more common in patients than in controls throughout the observation period $(p<0.002)$.

\section{[FIGURE 2]}

Internal medicine was the most frequented specialty, with $44 \%$ of patients paying a visit in the first year, decreasing to $21 \%$ in the fifth year. This was significantly higher than the $5 \%$ in controls. In the first year after diagnosis, many patients also had at least one visit with general surgery (44\%), which declined rapidly to 12 and $6 \%$ in the second and third year. Only $2 \%$ of the controls had a visit to general surgery in the 5 years.

\section{DISCUSSION}

Results of this study show that in the first 5 years after diagnosis, AYAs with cancer frequently visit non-cancer specialists and family physicians. The number of visits for both is by far the highest in the first year after diagnosis but remains higher than that in the general population sample up to 5 years after diagnosis. The large difference between the proportion of AYA cancer patients consulting a non-cancer specialist and the controls is notable, as generally, this age group does not have high levels of morbidity. Both family physicians and non-cancer specialists were often consulted for problems relating to their cancer. In addition, family physicians were often consulted for general symptoms and non-cancer specialists for discussion of results of lab tests.

Literature about non-oncology physician visits in AYAs with cancer is scarce. As far as we know, this is the first paper studying these visits in the first few years in this specific age group. In a related paper, we studied physician visits in the first 5 years after diagnosis of cancer in children under age 15 [25]. The most notable difference between AYA patients and children is that especially in the first year after diagnosis, AYA patients have considerably fewer non-cancer specialist visits, i.e., 9 per year versus 20 per year in children. This is not because AYAs generally pay fewer visits to non-oncology specialists than children, as the number of visits in the control groups is very similar, i.e., three per year. The number of non-cancer specialist visits decreases considerably faster in AYA patients than in children, suggesting that the problems generating these visits are not long term. Non-cancer specialist visits among AYAs are to a larger extent related to neoplasms, while the younger patients visit their non-cancer specialist for a variety of reasons, e.g., frequently discussing results of lab tests. This may be due to differences in cancer types (e.g., leukemia being frequent in younger patients vs. lymphomas in AYAs).

The frequency of family physician visits in AYA patients is similar to that in younger children. AYA patients often visit family physicians for problems relating to both neoplasms and general symptoms. They also visit family physicians for genitourinary problems and prenatal care, while in the younger children, otitis media was a common reason to visit a GP. This indicates that even in the first years after a 
Heins, M.J., Lorenzi, M.F., Korevaar, J.C., McBride, M.L. Non-oncology physician visits after diagnosis of cancer in adolescents and young adults. Journal of Cancer Survivorship: 2016, 10(4), 783-788

diagnosis of cancer, the family physician is visited for common age-specific health problems.

By linking clinical data from a large geographically identified cohort of AYAs with cancer to provincial health claims data, we obtained a complete picture of visits to family physicians and non-cancer specialists in a representative group of AYA cancer patients over several years without the potential for recall bias and selfselection, and patients were only lost to follow-up as they moved out of BC or died. The cohort had been established and followed several years ago; in the meantime, attention to the specific problems of AYAs with cancer has increased, so health care use may also have increased.

Physicians could only record one ICD code per visit. We may therefore have missed some health problems, but on the other hand, physicians will most likely have chosen the most relevant one. This does not mean that all ICD codes were informative, as in a relatively high percentage of family physician visits, the related ICD code was general symptoms $(14 \%)$. Although there may have been errors or lack of specificity in the diagnostic codes, it is not likely that errors will have differed systematically between patients and controls or between family physicians and non-cancer specialists. Besides, the percentage of contacts with a missing ICD code was low $(0.2 \%)$, which indicates good data quality.

Our data did not include visits to cancer specialists of the BC regional cancer centers. We therefore could not study the number of oncologist visits, which could have provided insight into possible substitution of care between oncologists and noncancer specialists or family physicians. However, if some non-therapy-related care was provided at cancer centers, this would mean that the care demands of this group were even higher than measured in this study, and in fact, there are limited resources at the cancer centers for this type of care.

It may be that the amount of physician visits is also importantly different between the younger members of the sample (many of whom would have been treated at BC Children's Hospital) and the older group. Unfortunately, we do not have information about the place where anti-cancer therapy was delivered, but we could divide between patients diagnosed at age 19 or younger (probably treated in the Children's Hospital) and those aged $>19$. Post hoc analyses showed no difference in the number of family physician visits, but the number of non-oncology specialist visits was indeed lower in those aged $>19$.

We found that, like younger cancer patients, in the first 5 years after diagnosis, AYAs have more non-cancer specialist and family physician visits than the general population of this age group. However, they also differ from younger patients, as they have fewer non-cancer specialist visits and these visits decline considerably faster over the years. A large proportion of both family physician and non-cancer specialist visits in AYA patients are for problems relating to cancer. In addition, family physicians are consulted for specific age-related problems, even in the first year after diagnosis. The family physician involvement in care for AYAs with cancer at this early stage should facilitate continuity of care at the time of transition from cancer center care to long-term care by the family physician. However, the pattern of physician visits of this age group calls for care that is tailored to their specific needs. 
Heins, M.J., Lorenzi, M.F., Korevaar, J.C., McBride, M.L. Non-oncology physician visits after diagnosis of cancer in adolescents and young adults. Journal of Cancer Survivorship: 2016, 10(4), 783-788

\section{COMPLIANCE WITH ETHICAL STANDARDS}

\section{Funding}

Funding for this study was received from the Canadian Institutes of Health Research, the Canadian Cancer Society (through the National Cancer Institute of Canada), and the Dutch Cancer Society.

\section{Conflict of interest}

The authors declare that they have no conflict of interest.

\section{Ethical approval}

All procedures performed in studies involving human participants were in accordance with the ethical standards of the institutional and/or national research committee and with the 1964 Helsinki Declaration and its later amendments or comparable ethical standards and Canadian legislation on privacy. BC Cancer Agency (BCCA) and BC Children's Hospital (BCCH) clinical Research Ethics Boards, both part of the University of British Columbia Research Ethics Board, approved of the study. BC Cancer Agency, BC Children's Hospital, and BC Ministry of Health approved access to and use of the data, facilitated by Population Data BC, for this study.

\section{Informed consent}

Given the large number of participants, obtaining individual informed consent was not feasible. To protect patient confidentiality, only de-identified linked files were available to the researchers and the Ministry of Health required suppression of cells with fewer than five patients in the text and tables.

\section{REFERENCES}

1. Hampton T. Cancer treatment's trade-off: years of added life can have long-term costs. JAMA. 2005;294:167-8.2. Canadian Cancer Society's Advisory Committee on Cancer Statistics. Canadian Cancer Statistics 2014. Toronto: Canadian Cancer Society; 2014.

3. Adolescent and Young Adult Oncology Progress Review Group. Closing the gap: research and care imperatives for adolescents and young adults with cancer (NIH Publication No. 06-6067). Bethesda MD: National Institutes of Health, National Cancer Institute, and the LiveStrong Young Adult Alliance, 2006.

4. Haase JE, Phillips CR. The adolescent/young adult experience. J Pediatr Oncol Nurs. 2004;21:145-9.

5. Thomas DM, Seymour JF, O’Brien T, Sawyer SM, Ashley DM. Adolescent and young adult cancer: a revolution in evolution? Int Med J. 2006;36:302-7.CrossRef

6. Zebrack B, Hamilton R, Smith AW. Psychosocial outcomes and service use among young adults with cancer. Semin Oncol. 2009;36:468-77.

7. Zebrack B, Bleyer A, Albritton K, Medearis S, Tang J. Assessing the health care needs of adolescent and young adult cancer patients and survivors. Cancer. 2006;107:2915-23.

8. $\quad$ Fritz GK, Williams JR. Issues of adolescent development for survivors of childhood cancer. J Am Acad Child Adolesc Psychiatry. 1988;27:712-5.

9. Madan-Swain A, Brown RT, Foster MA, et al. Identity in adolescent survivors of childhood cancer. J Pediatr Psychol. 2000;25:105-15.CrossRefPubMed

10. Kazak AE, Derosa BW, Schwartz LA, et al. Psychological outcomes and health beliefs in adolescent and young adult survivors of childhood cancer and controls. J Clin Oncol. 2010;28:2002-7. 
Heins, M.J., Lorenzi, M.F., Korevaar, J.C., McBride, M.L. Non-oncology physician visits after diagnosis of cancer in adolescents and young adults. Journal of Cancer Survivorship: 2016, 10(4), 783-788

11. Smith AW, Bellizzi KM, Keegan TH, et al. Health-related quality of life of adolescent and young adult patients with cancer in the United States: the adolescent and young adult health outcomes and patient experience study. J Clin Oncol. 2013;31:2136-45.

12. Phillips-Salimi CR, Andrykowski MA. Physical and mental health status of female adolescent/young adult survivors of breast and gynecological cancer: a national, population-based, case-control study. Support Care Cancer. 2013;21:1597-604.

13. Tai E, Buchanan N, Townsend J, Fairley T, Moore A, Richardson LC. Health status of adolescent and young adult cancer survivors. Cancer. 2012;118:4884-91.

14. Tonorezos ES, Oeffinger KC. Research challenges in adolescent and young adult cancer survivor research. Cancer. 2011;117:2295-300.

15. Zebrack B, Mathews-Bradshaw B, Siegel S, Alliance LYA. Quality cancer care for adolescents and young adults: a position statement. J Clin Oncol. 2010;28:4862-7.

16. Rebholz CE, Reulen RC, Toogood AA, et al. Health care use of long-term survivors of childhood cancer: the British Childhood Cancer Survivor Study. J Clin Oncol. 2011;29:4181-8.CrossRefPubMed

17. McBride ML, Lorenzi MF, Page J, et al. Patterns of physician follow-up among young cancer survivors: report of the Childhood, Adolescent, and Young Adult Cancer Survivors (CAYACS) research program. Can Fam Physician. 2011;57:e482-90.

18. Oeffinger KC, Mertens AC, Hudson MM, et al. Health care of young adult survivors of childhood cancer: a report from the Childhood Cancer Survivor Study. Ann Fam Med. 2004;2:61-70.

19. Shaw AK, Pogany L, Speechley KN, Maunsell E, Barrera M, Mery LS. Use of health care services by survivors of childhood and adolescent cancer in Canada. Cancer. 2006;106:1829-37.

20. Nathan PC, Hayes-Lattin B, Sisler JJ, Hudson MM. Critical issues in transition and survivorship for adolescents and young adults with cancers. Cancer. 2011;117:2335-41.

21. McBride ML, Rogers PC, Sheps SB, et al. Childhood, adolescent, and young adult cancer survivors research program of British Columbia: objectives, study design, and cohort characteristics. Pediatr Blood Cancer. 2010;55:324-30.

22. Rogers PC, De Pauw S, Schacter B, Barr RD. A process for change in the care of adolescents and young adults with cancer in Canada. "Moving to Action": The Second Canadian International Workshop. International Perspectives on AYAO, Part 1. J Adolesc Young Adult Oncol. 2013;2:72-6.

23. International classification of diseases and health related problems. Geneva: World Health Organization, 1992.

24. Lawless JF. Negative binomial and mixed Poisson regression. Can J Stat. 1987;15:209-25.

25. Heins MJ, Lorenzi MF, Korevaar JC, McBride ML. Non-oncology physician visits after diagnosis of cancer in children. BMC Family practice. 2016. (Accepted for publication). 
Heins, M.J., Lorenzi, M.F., Korevaar, J.C., McBride, M.L. Non-oncology physician visits after diagnosis of cancer in adolescents and young adults. Journal of Cancer Survivorship: 2016, 10(4), 783-788

\section{TABLES AND FIGURES}

Table 1 : Sociodemographic characteristics of patients and controls

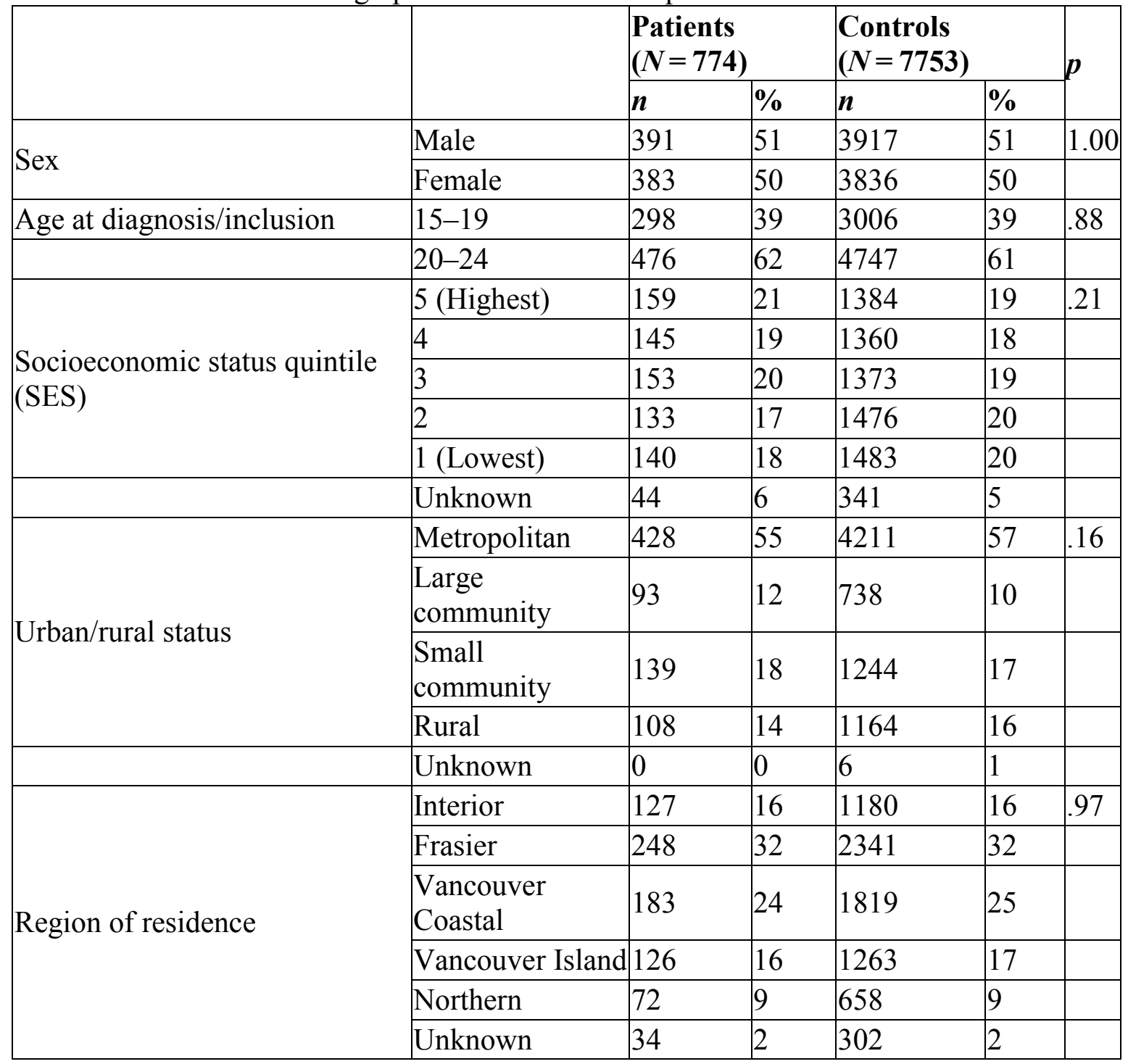


Heins, M.J., Lorenzi, M.F., Korevaar, J.C., McBride, M.L. Non-oncology physician visits after diagnosis of cancer in adolescents and young adults. Journal of Cancer Survivorship: 2016, 10(4), 783-788

Table 2: Clinical characteristics of patients $(N=774)$

\begin{tabular}{|l|l|l|l|}
\hline \multirow{4}{*}{ Calendar period of diagnosis } & N & $\%$ \\
\hline \multirow{5}{*}{ Diagnosis } & $1991-1995$ & 425 & 55 \\
\cline { 2 - 4 } & $1996-2000$ & 349 & 45 \\
\hline \multirow{5}{*}{ Treatment modality } & Lymphoma & 221 & 29 \\
\cline { 2 - 4 } & Carcinoma & 212 & 27 \\
\cline { 2 - 4 } & Germ cell & 140 & 18 \\
\cline { 2 - 4 } & Central nervous system & 51 & 7 \\
\hline & Soft tissue sarcoma & 42 & 5 \\
\hline & Leukemia & 40 & 5 \\
\hline & Bone & 25 & 3 \\
\hline & Other & 43 & 6 \\
\hline & Surgery only & 209 & 27 \\
\hline & Chemotherapy (chemo) & 192 & 24 \\
\cline { 2 - 4 } & Radiation (RT) & 51 & 7 \\
\cline { 2 - 4 } & Chemo and RT & 162 & 21 \\
\hline & Other/unknown & 160 & 21 \\
\hline Relapse status at end follow-up & Cancer free & 711 & 92 \\
\hline & Relapse/secondary cancer & 63 & 8 \\
\hline
\end{tabular}

Table 3 :Proportion of patients and controls with at least one physician visit and mean (SD) no. of visits by time since diagnosis

\begin{tabular}{|c|c|c|c|c|c|c|c|c|c|c|c|c|c|c|c|c|c|}
\hline \multirow[b]{2}{*}{ Visits } & & \multicolumn{3}{|c|}{ Year 1} & \multicolumn{3}{|c|}{ Year 2} & \multicolumn{3}{|c|}{ Year 3} & \multicolumn{3}{|c|}{ Year 4} & \multicolumn{3}{|c|}{ Year 5} & \multirow{2}{*}{$\begin{array}{l}p \\
\text { Trend }\end{array}$} \\
\hline & & $N$ & $\%$ & $\begin{array}{l}\text { No. of } \\
\text { visits }\end{array}$ & $N$ & $\%$ & \begin{tabular}{|l|} 
No. \\
of \\
visits
\end{tabular} & $N$ & $\%$ & \begin{tabular}{|l|} 
No. \\
of \\
visits \\
\end{tabular} & $N$ & $\%$ & $\begin{array}{l}\text { No. of } \\
\text { visits }\end{array}$ & $N$ & $\%$ & $\begin{array}{l}\text { No. of } \\
\text { visits }\end{array}$ & \\
\hline \multirow[t]{2}{*}{ All visits } & Patients & 771 & $100^{*}$ & $\begin{array}{l}18.4 \\
(14.4)^{*}\end{array}$ & 715 & $93 *$ & $\begin{array}{l}10.0 \\
(9.5)^{*}\end{array}$ & 677 & $90 *$ & $\mid \begin{array}{l}9.0 \\
(8.3) *\end{array}$ & 655 & $88^{*}$ & $\begin{array}{l}8.9 \\
(10.3) *\end{array}$ & 642 & $87 *$ & $\mid \begin{array}{l}9.4 \\
(11.2) *\end{array}$ & $<0.001$ \\
\hline & Controls & 6236 & 80 & $\begin{array}{l}6.6 \\
(6.9)\end{array}$ & 6143 & 80 & \begin{tabular}{|l|}
6.7 \\
$(7.2)$
\end{tabular} & 6014 & 80 & \begin{tabular}{|l|}
6.8 \\
$(7.5)$
\end{tabular} & 5866 & 678 & $\begin{array}{l}7.1 \\
(8.6)\end{array}$ & 5786 & 79 & \begin{tabular}{|l|}
7.3 \\
$(8.9)$
\end{tabular} & $<0.001$ \\
\hline \multirow[t]{2}{*}{$\begin{array}{l}\text { Family } \\
\text { physician }\end{array}$} & Patients & 745 & $96 *$ & $\begin{array}{l}9.7 \\
(8.6)^{*}\end{array}$ & 687 & $89 *$ & $\mid \begin{array}{l}6.9 \\
(7.0)^{*}\end{array}$ & 637 & $85 *$ & $\left|\begin{array}{l}6.8 \\
(6.3)^{*}\end{array}\right|$ & 634 & $85^{*}$ & $\mid \begin{array}{l}6.8 \\
(8.3)^{*}\end{array}$ & 617 & $84 *$ & $\begin{array}{l}7.3 \\
(9.5)^{*}\end{array}$ & $<0.001$ \\
\hline & Controls & 6105 & 79 & $\begin{array}{l}5.6 \\
(5.7)\end{array}$ & 6036 & 78 & \begin{tabular}{|l|}
5.7 \\
$(5.9)$
\end{tabular} & 5891 & 78 & \begin{tabular}{|l|}
5.8 \\
$(6.3)$
\end{tabular} & 5769 & 977 & $\begin{array}{l}6.0 \\
(6.9)\end{array}$ & 5690 & 77 & $\begin{array}{l}6.1 \\
(7.3)\end{array}$ & $<0.001$ \\
\hline \multirow[t]{2}{*}{$\begin{array}{l}\text { Non- } \\
\text { cancer } \\
\text { specialist }\end{array}$} & Patients & 743 & $96 *$ & $\begin{array}{l}9.4 \\
(10.6)^{*}\end{array}$ & 493 & $64 *$ & $\left|\begin{array}{l}4.8 \\
(5.2)^{*}\end{array}\right|$ & 433 & $57 *$ & $\left|\begin{array}{l}4.0 \\
(4.5)^{*}\end{array}\right|$ & 406 & $54^{*}$ & $\mid \begin{array}{l}3.9 \\
(5.8)^{*}\end{array}$ & 357 & $49^{\prime}$ & $\mid \begin{array}{l}4.2 \\
(5.8)^{*}\end{array}$ & $<0.001$ \\
\hline & Controls & 2272 & & $\begin{array}{l}3.0 \\
(3.8)\end{array}$ & 2158 & 28 & $\begin{array}{l}3.1 \\
(4.1)\end{array}$ & 2189 & 29 & $\begin{array}{l}2.9 \\
(4.0)\end{array}$ & 2152 & 29 & $\begin{array}{l}3.3 \\
(5.7)\end{array}$ & 209 & 28 & $\begin{array}{l}3.5 \\
(5.6)\end{array}$ & $<0.001$ \\
\hline
\end{tabular}


Heins, M.J., Lorenzi, M.F., Korevaar, J.C., McBride, M.L. Non-oncology physician visits after diagnosis of cancer in adolescents and young adults. Journal of Cancer Survivorship: 2016, 10(4), 783-788

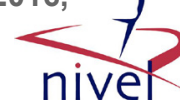

No. of visits is the mean number (standard deviation) of visits of those who had at least one visit

${ }^{*} p \leq 0.001$, all comparisons between patients and controls are statistically significant

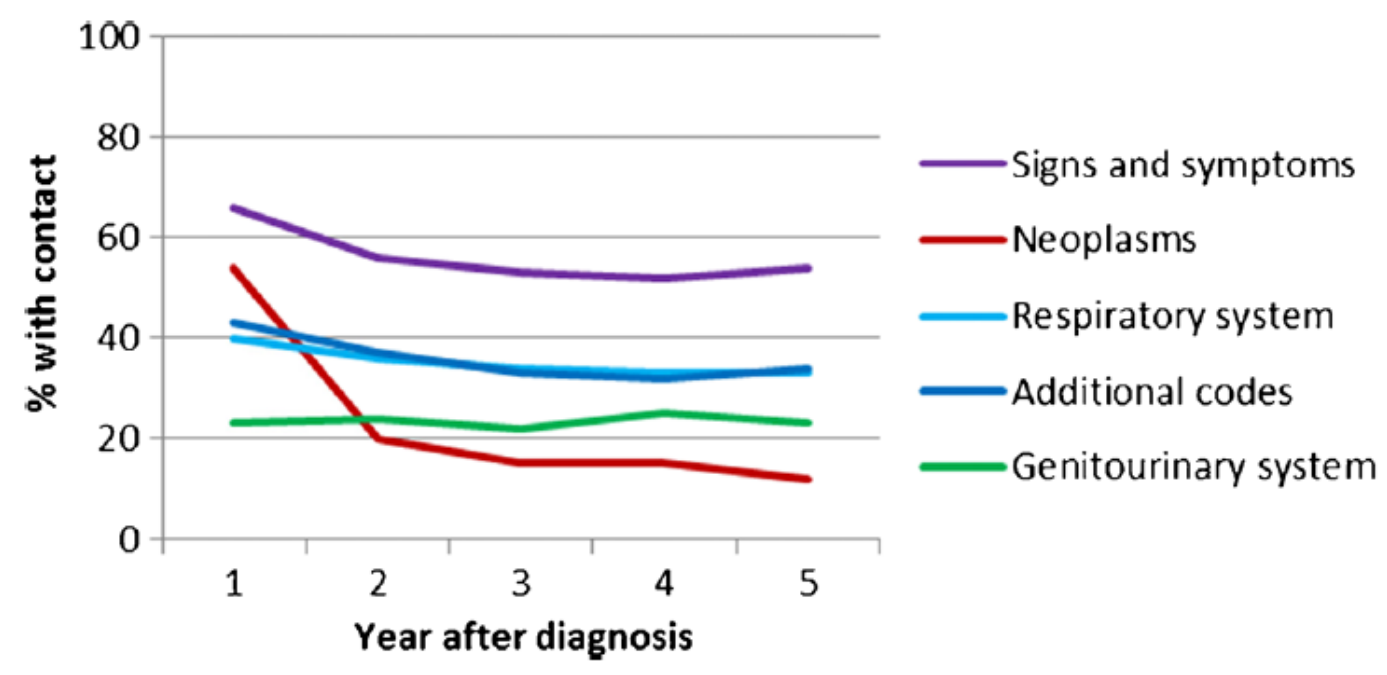

Fig. 1 Proportion of patients with family physician contact, by reason for visit (5 most frequent)

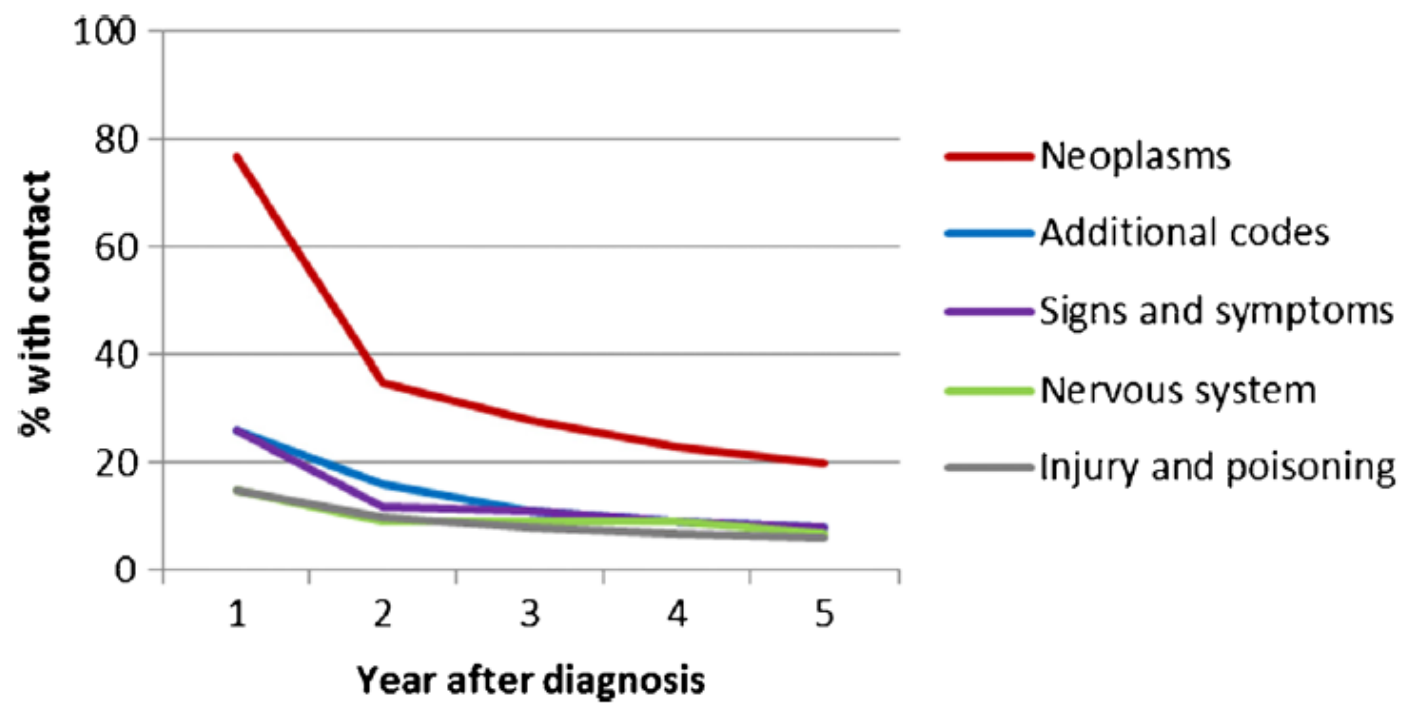

Fig. 2 Proportion of patients with non-oncology specialist contact, by reason for visit (5 most frequent) 


\section{Supporting Information " Health care use after diagnosis of cancer in}

AYAs'

Appendix 1: Most frequent ICD codes by chapter for family physician visits.

\begin{tabular}{|c|c|c|c|}
\hline \multicolumn{4}{|l|}{ family physician visits } \\
\hline \multirow[t]{5}{*}{ Signs \& symptoms } & General symptoms & 1611 & 24.3 \\
\hline & Symptoms involving nervous and musculoskeletal systems & 959 & 14.5 \\
\hline & Symptoms involving skin and other integumentary tissue & 832 & 12.6 \\
\hline & Other symptoms involving abdomen and pelvis & 591 & 8.9 \\
\hline & Symptoms involving head and neck & 577 & 8.7 \\
\hline \multirow[t]{5}{*}{ Respiratory system } & $\begin{array}{l}\text { Acute upper respiratory infections of multiple or unspecified } \\
\text { site }\end{array}$ & 471 & 17.2 \\
\hline & Acute pharyngitis & 395 & 14.4 \\
\hline & Acute nasopharyngitis (common cold) & 333 & 12.1 \\
\hline & Acute bronchitis and bronchiolitis & 306 & 11.2 \\
\hline & Bronchitis not specified as acute or chronic & 194 & 7.1 \\
\hline \multirow[t]{5}{*}{ Additional codes } & Laboratory & 1971 & 33.4 \\
\hline & Prenatal care & 1291 & 21.9 \\
\hline & Contraceptive advice & 533 & 9.0 \\
\hline & Anxiety/depression & 446 & 7.6 \\
\hline & Abdominal pain & 317 & 5.4 \\
\hline \multirow{5}{*}{$\begin{array}{l}\text { Genitourinary } \\
\text { system }\end{array}$} & Disorders of menstruation & 622 & 30.3 \\
\hline & Inflammatory disease of cervix, vagina and vulva & 233 & 11.4 \\
\hline & Cystitis & 228 & 11.1 \\
\hline & Other disorders of female genital organs & 150 & 7.3 \\
\hline & Other disorders of urethra and urinary tract & 123 & 6.0 \\
\hline
\end{tabular}


Appendix 2: Most frequent ICD codes by chapter for non-cancer specialist visits.

\begin{tabular}{|c|c|c|c|}
\hline ICD chapter & ICD code & $\mathrm{N}$ & $\%$ \\
\hline \multirow[t]{5}{*}{ Signs \& symptoms } & Symptoms involving respiratory system & 190 & 15.3 \\
\hline & General symptoms & 146 & 11.7 \\
\hline & Symptoms involving nervous and musculoskeletal systems & 143 & 11.5 \\
\hline & Symptoms involving head and neck & 139 & 11.2 \\
\hline & Symptoms involving digestive system & 79 & 6.4 \\
\hline \multirow[t]{5}{*}{ Additional codes } & Laboratory & 2581 & 78.3 \\
\hline & X-Ray & 163 & 4.9 \\
\hline & Prenatal care & 157 & 4.8 \\
\hline & Ear tests & 154 & 4.7 \\
\hline & Abdominal pain & 60 & 1.8 \\
\hline \multirow[t]{5}{*}{ Nervous system } & Epilepsy & 93 & 10.5 \\
\hline & Other and unspecified disorders of the nervous system & 54 & 6.1 \\
\hline & Other retinal disorders & 51 & 5.8 \\
\hline & Strabismus and other disorders of binocular eye movements & 51 & 5.8 \\
\hline & Disorders of refraction and accommodation & 44 & 5.0 \\
\hline \multirow[t]{5}{*}{ Injuries \& poisoning } & Complications of medical care, not elsewhere classified & 670 & 55.4 \\
\hline & Other complications of procedures, not elsewhere classified & 41 & 3.4 \\
\hline & Fracture of radius and ulna & 34 & 2.8 \\
\hline & Other and unspecified complications of medical care & 32 & 2.6 \\
\hline & Sprains and strains of ankle and foot & 32 & 2.6 \\
\hline
\end{tabular}

